\title{
Contradicciones y desafíos de la globalización para la Educación Social
}

\author{
Rosa $M^{\underline{a}}$ Rodríguez Izquierdo
}

Universidad Pablo de Olavide

\section{Resumen}

En la primera parte de este artículo presentamos una aproximación a la globalización como uno de los nuevos escenarios socioculturales de nuestro tiempo. La autora describe la exclusión social, que provocan necesariamente nuevas formas de desigualdad y marginación. Se dedica también un apartado a presentar las contradicciones y oportunidades de la globalización y a sus consecuencias. Por último, finalizamos con el análisis de algunos de los retos que comporta esta nueva realidad para la educación social.

Palabras Clave: Educador social, globalización, inclusión, educación de calidad para todos, ciudadanía intercultural, comunidades de aprendizaje.

\section{Summary}

In the first part of this paper, we present an approach to globalization as one of the new sociocultural sceneries in contemporary world. The author describes the process of social exclusion that determine necessarily new forms of inequal ity and exclusion. The work also offers the contradictions and opportunities of globalization and its consequences. Finally, the article ends with an analysis of some of the challenges of this new reality with which social educators will meet.
KEY WORDS: Social educator, globalization, inclusion, quality of education for all, intercul tural citizenship, learning communities.

\section{Vivimos bajo el signo de la globalización}

La globalización es una metáfora que expresa la ruptura de lo local y la mundialización de todas las esferas de la actividad humana. Hoy todos somos corresponsables e interdependientes y es imposible el aislamiento. Todo lo que sucede en cualquier rincón del planeta de algún modo nos atañe. Nos hemos convertido en ciudadanos del mundo sin dejar de ser hijos de la aldea. El mismo día se ven las mismas noticias y los mismos videoclips en todos los rincones del mundo, se exhiben los mismos ídolos del deporte, la música o la moda, se consumen los mismos productos. El Informe Delors (1996: 59) de la UNESCO de la Comisión Internacional sobre la educación para el siglo XXI llama la atención sobre un hecho nuevo: "estamos pasando de la comunidad de base a la sociedad mundial".

La idea de una cultura global es paralela al proceso de globalización reciente. En un principio se creía que el avance global de la actualidad produciría inevitablemente una cultura mundial más homogénea, pero la realidad demuestra que, a pesar de que el mundo está cada vez más interconectado (económica, 
política y culturalmente), las diferencias culturales aumentan, o más preciso sería decir que el actual proceso de globalización conduce a un aumento de la sensibilidad ante las diferencias.

Antes del "descubrimiento" de América, hace apenas cinco siglos, en Europa teníamos una concepción del mundo que no iba más allá del horizonte físico. Hoy, el Center for Global Education $^{1}$ muestra en su página web sobre programas de estudios la expresión "Let the world be your classroon!". A Cristóbal Colón le llevó más de dos meses cruzar el Atlántico. Hoy, nos lleva pocos segundos llegar a cualquier parte del mundo. Siempre hubo contactos interculturales a lo largo de las épocas. Lo nuevo hoy es que los contactos se han sistematizado, se hacen permanentes y se aceleran hasta posibilitar una interacción instantánea, en tiempo real.

La interdependencia planetaria, el esquema Norte-Sur, en lo político, han ido acompañados, algo tardíamente, por la expansión de las empresas a la par que la integración de las economías y los sistemas financieros, expre sado ortodoxamente como el fenómeno de la globalización. La globalización nace como un concepto económico en un contexto político mundial.

No es mi intención debatir sobre lo anterior, sólo lo incluyo como un marco de referencia. Sin embargo, cabe destacar algunos de los múltiples aspectos de la globalización:

u La globalización es un enfoque o modelo de la realidad. Integra las concepciones/dimensiones "micro" $y$ "macro", a través de una forma diferente de pensar, actuar y concebir el mundo. Los educadores, por ejemplo, debemos ser conscientes que en el siglo XXI el mundo en el que debemos intervenir es diferente, que está en constante cambio y que los acontecimientos que ocurren en un lugar, cotidiana mente, están relacionados con los acontecimientos que se presentan en lugares remotos. u La globalización es un atributo o caracterís- tica de lo que ocurre en la realidad; ahora de modo incipiente, pero cada vez con mayor intensidad y alcance. La globalización no es sólo una teoría, es también una realidad.

u La globalización ha permitido, y muchas veces ha promovido, un cambio radical en la concepción de la educación, asociada a expresiones como la era de la información o la sociedad del conocimiento. Hoy más que nunca se puede percibir las limitaciones del enfoque educativo formal, centrado en la enseñanza, centralizado en el "aula física" y con un profesor delante. Enfoque aún predominante en la mayoría de las realidades educativas.

La pregunta que nos debemos hacer como educadores es: ¿Está la Educación Social aportando los criterios adecuados para que los jóvenes de hoy puedan, el día de mañana, enfrentar de manera efectiva el mundo complejo, contradictorio, cambiante que nuestra generación les está heredando? ¿Qué cambios necesita hacer la educación para que pueda procederse a una globalización responsable, con conciencia social, con solidaridad universal, con respeto al mundo de la naturaleza, con esperanza para las generaciones del mañana?

\subsection{Contradicciones y oportunidades de la globalización}

Para algunos, la globalización no solamente es un nuevo hecho histórico, sino ante todo una oportunidad para romper viejos amarres, para compartir el progreso y el bienestar a escala mundial. Esta es, tal vez, la visión optimista de las cosas. Pero no todos ven la tendencia a la globalización con el mismo entusiasmo. Existen también nubarrones en el cielo. La globalización, la integración mundial, tiene también aspectos nega ti vos y destructivos, o cuando menos altamente problemáticos y cuestionables.

Si bien es verdad que la globalización como tal no implica una connotación negati- 
va; más bien ofrece inmensas posibilidades para el desarrollo de la humanidad. Pero cuando no se respetan los valores más fundamentales de la persona humana -como ocurre en el campo económico con la absolutización del libre mercado-, la globalización resulta verdaderamente nefasta, especialmente para los colectivos más vulnerables.

En primer lugar, porque el proceso globalizador es impulsado desde las economías industriales más adelantadas, que acusan los más altos ingresos per cápita, y que concentran la capacidad y el poder para beneficiarse de este proceso. En el otro extremo de la escala del producto nacional bruto, se encuentran los países pobres, o como se llaman eufemísticamente en el lenguaje de las Naciones Unidas, los países "menos adelantados" que se integran a la globalización, por decirlo de alguna manera, en el piso más bajo, y cuyos beneficios por este proceso son, en el mejor de los casos, marginales. En segundo lugar, porque la máquina arrolladora de la globalización es promovida por una idea fundamental, una idée fixe, que es el crecimiento económico a ultranza, el aumento del producto bruto, sin considerar costos de tipo social, cultural o ambiental.

El mundo de comienzos del siglo XXI funciona para unos pocos y contra muchos. Con la globalización de la economía hay unos ganadores, los ricos, y unos perdedores claros, los pobres. Esto ocurre a nivel mundial, entre países y a nivel de personas dentro de cada país. En esta brutal competencia internacional por los mercados y los beneficios, no sólo hay millones de seres humanos que quedan tirados a un lado del camino, viendo pasar el tren de la prosperidad, sino también muchas y variadas formas de vida (desde los pueblos indígenas y tribales con sus culturas ancestrales, las sociedades campesinas autosuficientes, el artesanado tradicional, las pequeñas empresas familiares, que en total suman miles de millones de seres humanos, sobre todo en África, Asia y América Latina) que se ven súbi- tamente destinadas a desaparecer con pocas perspectivas alternativas para su futuro.

Para captar la ilusión que se esconde tras la globalización, el informe del Programa de las Naciones Unidas para el Desarrollo (1997: 92) utilizaba esta metáfora: "la globalización es una marea de riquezas que supuestamente levanta a todos los barcos; los trasatlánticos y yates poderosos navegan bien, los barcos pequeños hacen agua, las canoas y barquitos se hunden. Y es que si bien la globalización es inclusiva como mercado, es decir, el consumo, la información, los productos para el ocio y la diversión se expanden sin fronteras y tienden a llegar a todos los rincones del mundo, es excluyente de todos aquellos, que son la mayoría, que no tienen capacidad de adquirir esos bienes que la publicidad vocifera y ofrece a manos llenas, y que incluso tienen negado el acceso a los bienes y servicios fundamentales".

Esta globalización darwinista, selectiva y excluyente, más que una globalización implica una dualización, por haber creado una sociedad antagónica entre el Norte y el Sur, los ricos y los pobres, los que saben y no saben, los blancos y los de color, el hombre y la mujer, el derroche del consumo presente frente a la crisis de sostenibilidad ambiental, entre el "West and the Rest".

Resulta innegable a todas luces que el triunfo planetario de la riqueza y poder no es igualitario.

Ante la brecha de opulencia y miseria entre países del Norte y del Sur, nadie sensato duda de la necesidad de compensar las desigualdades provocadas por una globalización desregulada y salvaje. En palabras sencillas se diría que los males de la globalización sólo puede curarlos una mejor globalización. En palabras de Friedman (1999: 362): "No hay otra alternativa pero necesitamos humanizar su rostro".

Para concluir, la globalización en un mundo cada vez más interdependiente tiene efectos diversos en los distintos sectores y grupos de población. No es este el lugar adecuado para un análisis más detallado de 
dichos efectos, que sería por demás largo y complicado. Sin embargo de momento, aunque esta tendencia augura un gran potencial para beneficio de la humanidad, también es cierto que conlleva y genera a su vez problemas y conflictos sociales en aumento: La exclusión social.

\section{Retos de la Educación Social en el mundo globalizado}

Somos muy conscientes de que en la actualidad, las ideas de "emancipación" o "liberación", tan propias de la educación social, son ajenas al discurso de la postmodernidad, que ha proclamado el fin de las utopías e incluso de la historia. Además, reconocemos también que vivimos en unos tiempos en que se está poniendo de moda el desencanto, el pasotismo y la desesperanza; en que el pragmatismo está acabando con los ideales y los sueños, y el egoísmo e individualismo están siendo considerados como valores esenciales. Somos conscientes, por ello, de que ciertos discursos y propuestas, pueden parecer ilusas, inocentes e incluso idealistas.

Sin embargo, pensamos que es en este contexto, y a pesar de correr el riesgo de la utopía, donde se hace necesaria la ilusión y la convicción de que otro mundo es posible y de que desde la educación social podemos aportar algo. Si no tenemos esperanza e ilusión, esta mos muertos como educadores.

Por ello, hoy se habla con insistencia de la necesidad de repensar la educación social y de iniciar procesos de deconstrucción de teorías y prácticas que amparan desigualdades y posturas de dominación. Borjas (2000: 97) entiende la deconstrucción como: "reconstruir los procesos desde contextos precisos, desde las micro narraciones en búsqueda de transformaciones en la cotidianidad de las personas y de los grupos convirtiendo el espacio cultural en el campo de batalla en el que hombres y mujeres serán sujetos de cambios que conduzcan a transfor- maciones sociales... Adquieren así especial relevancia los procesos de diálogo, consenso, negociación cultural que permitan rehacer tejidos sociales de convivencia y solidaridad... Desde sus historias particulares de vida los sujetos reconocen que sus asuntos personales no pueden estar de espaldas a los objetivos que se proponen. Lo personal se hace político. Lo político incorpora lo que sucede en el ámbito de los doméstico, de las relaciones entre hombres y mujeres, de las relaciones de poder en cualquiera de sus dimensiones. La acción educativa será así vivencia de participación y escuela de democracia".

La pregunta impostergable en nuestros días es ¿cómo abordar hoy una práctica y un pensamiento emancipador en un contexto de globalización, neoliberalismo y postmodernidad? ¿Cómo construir propuestas concretas de dignificación y de empoderamiento ${ }^{2}$ ? Porque si bien hoy debemos movernos con las certezas de nuestras incertidumbres, si algo resulta de una claridad meridiana en medio de tanta confusión es que cada día aumenta el número de excluidos, y por ello se hace cada vez más necesaria una auténtica educación social que capacite para vivir con dignidad y ejercer sus derechos de ciudadanía.

La educación social defiende la vocación histórica de cada hombre y de cada mujer como artífices de futuro, el valor humano de la utopía, y rechaza y combate "el pensamiento único". Perder la capacidad de soñar y de sorprenderse es perder el derecho a actuar como ciudadanos, como autores y actores de los cambios necesarios a nivel político, económico, social y cultural. Pensamos que es tiempo de defender con tesón y con pasión el valor de la esperanza y en este mundo globalizado, de atrevernos a soñar y proponer la globalización de la solidaridad y de la esperanza y luchamos por poner de moda la solidaridad. Por ello, frente al Pienso, luego existo cartesiano, raíz de la modernidad, y el Compro, luego existo, basamento del mundo globalizado, levantamos, como nos lo propone González 
Lucini (1996), el Sueño, luego existo, de la esperanza comprometida.

Desde esta perspectiva nos atrevemos a señalar algunos desafíos esenciales que se nos presentan hoy desde la educación social, sabiendo que no son los únicos y que el necesario debate sigue abierto. La falta de espacio nos va a impedir desarrollarlos como hubiéramos deseado.

\section{1. El reto de la inclusión}

Existe el peligro real de que la educación, en vez de ser un medio para democratizar la sociedad, lo sea para agigantar las diferencias: buena educación para los que tienen posibilidades económicas y capacidad para exigir, y pobre educación para los más excluidos ${ }^{3}$. Si queremos evitar que la educación reproduzca y perpetúe la pobreza, debemos garantizarles una educación que evite su fracaso y que prepare a los sujetos para desenvolverse eficazmente en el mundo del trabajo y de la vida, de modo que después la sociedad no los margine.

No va a ser nada fácil evitar el fracaso de los más débiles en un mundo que está organizado para reproducirlo en palabras de Bordiesu y Passeron (1977). De hecho, la educación reproduce las desigualdades mientras legitima las instituciones que la recrean. ¿Cómo hacer para que los centros educativos dejen de ser mecanismos para la selección y exclusión, y se conviertan en instituciones para la inclusión y la coherencia social? ¿Cómo leer el fracaso desde la escuela y desde la sociedad y no desde los alumnos? ¿Cómo dejar de preguntarnos por qué fracasan en la escuela la mayoría de los alumnos en riesgo de exclusión, y preguntarnos más bien por qué fracasa la escuela con estos alumnos? Detrás de cada alumno que fracasa, se oculta el fracaso del sistema educativo, el fracaso de la escuela, el fracaso del educador y la familia. Posiblemente el alumno fracasa porque no somos capaces de brindarle lo que necesita. De ahí la necesidad de practicar la discriminación positiva, es decir, privilegiar y aten- der mejor a los que tienen más carencias, para así compensar en lo posible las desigualdades y evitar agrandar las diferencias. No puede ser que abandonen la escuela precisamente los que más necesitan de ella. En este sentido, Estado y sociedad deben aunar esfuerzos para que en los centros educativos que atienden a los alumnos más necesitados, se les garantice a todos la misma calidad educativa, o incluso mayor, que la que obtienen los alumnos de las familias pudientes. Esto implica compensar las ausencias y desventajas sociales proporcionándoles buenas bibliotecas, comedores escolares, acceso a ordenadores y conexión a Internet, laboratorios, canchas deportivas, lugares para estudiar e investigar con comodidad, actividades extraescolares significativas, y también de los mejores educadores, capaces de promover una pedagogía que, reconozca los saberes y valores del alumno y promueva su motivación y autoestima.

Plantearnos la inclusión de los excluidos y la superación del fracaso escolar implica también atender preferentemente a los niños y jóvenes que nunca fueron a la escuela o la abandonaron antes de tiempo. Su paso por el sistema educativo sólo sirvió para marcarles con la conciencia de perdedores. De allí la necesidad de abordar e implantar múltiples programas educativos, formales y no formales, que levanten su autoestima y los capaciten laboral, humana y políticamente para que no sólo sean buenos trabajadores, sino también buenos ciudadanos y agentes democratizadores.

\section{2. El reto de una educación de calidad para todos}

Hoy hay que garantizar a todos, especialmente a los más colectivos más vulnerables, que no tienen medios para obtener la educación por sí mismos, una educación de calidad. Educación que permita a todos sin excepción el desarrollo de todas sus cualidades y capacidades creativas, de modo que cada uno pueda responsabilizarse de sí mismo. 
La educación social debe estar muy atenta porque el discurso de la calidad no se reduzca a un problema técnico, de especialistas y expertos. Como apunta Escudero (1999), la concepción de calidad que predomina está atrapada en la lógica de la producción, la rentabilidad y el mercado. De hecho, las propuestas humanistas de calidad que suelen proclamarse, se diluyen a la hora de la verdad, donde se imponen meramente los indicadores de rentabilidad y eficiencia. Dado que la educación no es una mercancía, no podemos permitir su secuestro por la mentalidad mercantil. Por ello, la Educación social debe trabajar por una concepción de calidad en torno a metas sociales, políticas, democráticas y humanistas. Concepción de una educación atenta al desarrollo personal de los individuos, sus capacidades de comprensión y análisis de la sociedad en la que viven, su desarrollo humano y personal en el contexto del desarrollo social y comunitario, inspirado en principios y valores como la igualdad, la equidad y la emancipación social y humana. Calidad, en definitiva, asociada a la voluntad política de ir convirtiéndola en un servicio público universal, compensador, o al menos atenuante de las desigualdades.

En palabras de Tedesco (1995: 73): "ningún sistema basado en la exclusión y el autoritarismo puede ser sustentable en el largo plazo. Es por eso por lo que la demanda de calidad para todos, basada en el supuesto según el cual todos los seres humanos son capaces de aprender, constituye la alternativa socialmente más legítima. Esta exigencia de democratización en el acceso al dominio de las competencias socialmente más significativas tiene, además de un componente ético, un evidente fundamento sociopolítico".

\subsection{El reto del fortalecimiento de los sujetos y las comunidades}

En un mundo que nos invita al individualismo consumista como modo de lograr la iden- tidad y realización plena, que canibaliza nuestras relaciones e impone el darwinismo social (la supervivencia de los más fuertes) y moral (los pobres son culpables de su pobreza), que pretende degradar a los ciudadanos a meros consumidores y clientes, la finalidad de la educación social debe ser, según Pérez Gómez (1998), la emergencia y el fortalecimiento del sujeto, lo que supone la defensa de la libertad personal y el desarrollo de la comunidad. Entendemos que se es sujeto en la medida en que uno va responsabilizándose de sus emociones y acciones, en la medida en que va tomando posesión de la propia vida y se va liberando de las dependencias y ataduras. Se trata de ayudar a sacar lo mejor de uno mismo, de ayudar a nacer al hombre o la mujer que todos llevamos dentro.

En nuestro mundo, cada día parecen escasear más y más los sujetos autónomos, capaces de darle sentido a su vida y de vivirla con plenitud. La mayoría vive por los demás (mercado, modas, costumbres, objetos, rutina, dinero, dirigentes...), sin plantearse ser "señores" de sí mismos. No son autores de su proyecto de vida, sino meros actores de un guión escrito por otros. La libertad, que es autonomía responsable, y superación de caprichos y ataduras de modo que nada ni nadie tenga poder sobre uno, se viene confundiendo cada vez más con la capacidad de responder a las sugerencias y orientaciones del mercado, y a la satisfacción del instinto continuamente estimulado por él. Se confunde, en definitiva, con su contrario: la total dependencia.

Entendemos que la educación social debe ser capaz de gestar una propuesta educativa capaz de formar sujetos de vida digna y de ciudadanía responsable, capaces de construir en colectivo la propia historia. En términos freirianos, nos referimos a una práctica educativa orientada a desarrollar "la capacidad de leer la realidad, decir la propia palabra y escribir la historia de la liberación personal y comunitaria". Se trata, en definitiva, de una propuesta ética, política y pedagógica de transformación 
para la construcción de una democracia integral, cimentada sobre la vivencia de los derechos humanos fundamentales y el cumplimiento responsable de los deberes y obligaciones. Democracia, en consecuencia, participativa y social, en la que se respetan la diversidad y las diferencias, capaz de garantizar a todos el disfrute de los bienes de la modernidad y el pleno ejercicio de la ciudadanía.

\section{4. El reto de la convivencia y ciudadanía intercultural}

En nuestra cultura de la diversidad y el pluralismo, la educación social debe promover y garantizar las competencias fundamentales para una sana convivencia y para el ejercicio de una ciudadanía responsable:

u Aprender a resolver los conflictos mediante la negociación y el diálogo, de modo que todos salgan beneficiados de él, tratando de convertir la diversidad en fuerza positiva, fuerza para la creación y cooperación, y no para la exclusión.

u Aprender a comunicarse, a dialogar, a escuchar al otro como portador de verdad. Si yo creo que tengo toda la verdad, no escucho, sino que impongo mi verdad que el otro deberá aceptar. Hoy día hablamos y hablamos pero cada vez nos escuchamos menos. Hablamos pero no nos esforzamos por entender lo que el otro trata de decirnos. De ahí la importancia de que todos aprendamos a conversar, escuchar, expresarse con libertad, aclarar, comprender al otro y lo que dice, defender con firmeza las propias convicciones sin agredir ni ofender al que nos contradice. Una comunidad que aprende a conversar, aprende a convivir. Como afirma Freire (1970: 123): "no podemos ser verdaderamente humanos sin comunicación... Impedir la comunicación es reducir a la gente al estatus de cosas".

u Aprender a interactuar con los otros, a valorar y aceptar las diferencias culturales, sociales y de género, sin convertirlas en desigual- dades. Precisamente porque todos somos iguales, todos tenemos derecho a ser diferentes. Aprender a trabajar juntos, a decidir en grupo, a considerar los problemas como retos a resolver y posibilidades de crear juntos soluciones creativas y no como ocasiones para culpabilizar a otros.

u Aprender a cuidarse, a cuidar de los otros y a cuidar del ambiente, las cosas colectivas, los bienes públicos que pertenecen a todos, combatiendo el desinterés por lo público. Aprender a esforzarse y a trabajar con responsabilidad, medio esencial para garantizar a todos unas condiciones de vida digna (vivienda, alimentación, escuela, trabajo, ocio...) como factores esenciales para la convivencia pacífica. Si los demás no tienen condiciones de vida adecuadas y apenas sobreviven, no será posible la convivencia. Por ello, hay que entender que la defensa de los derechos humanos fundamentales se transforma en el deber de hacerlos posibles para todos.

u Aprender a valorar la propia familia, cultura y religión, a ser conscientes de sus raíces, y a respetar las familias, culturas y religiones diferentes, combatiendo los dogmatismos, fundamentalismos e intolerancia de quienes quieren imponer una única forma de pensar, de creer y de vivir. La diversidad y el respeto a las minorías es tan importante como el gobierno de las mayorías.

u Aprender a desarrollar la autonomía personal, la confianza, el respeto, la autoresponsabilidad y la corresponsabilidad, el compromiso personal y social, la cooperación y la solidaridad. En definitiva, sólo será posible convivir, es decir vivir con los demás, si hay personas dispuestas a vivir para los demás.

\section{5. El reto de las comunidades de aprendizaje}

No basta con aprender a leer la realidad. El objetivo de la educación social es transformar esa realidad, humanizarla. De todo lo anterior, hay algo que es claro y evidente, la escue- 
la no puede llevar todo el peso de la integración. Para alcanzar los nuevos fines de la educación esta institución requiere un nuevo modelo de organización y un nuevo modo de relación con los servicios educativos especiales y los servicios sociales, nuevos recursos materiales y humanos, y voluntad de incorporar nuevas metodologías que tengan en cuenta la diversidad.

Esto supone entender y asumir los centros educativos ya no como lugares donde los docentes van a enseñar, los alumnos a aprender y la comunidad llega hasta el portón; sino como lugares donde todos, alumnos, docentes y comunidad, van a aprender a valerse por sí mismos, a organizarse, a resolver sus problemas, a producir propuestas e iniciativas, a crear arte, ciencia y tecnología, a celebrar su cultura y sus creencias como expresión que les permita decirse y decirle a los demás lo que son, sienten y quieren, y de este modo mejorar su calidad de vida e ir fraguando una sociedad más participativa y más justa para todos.

Serían muchos los factores que explican la expansión de las comunidades de aprendizaje, entre otros, Torres (2001) destaca el desencanto con el sistema escolar y con los reiterados intentos de reforma educativa (escolar), y la búsqueda de vías y modos nuevos para pensar la educación escolar y la educación en general (emerge por todos lados el reclamo por un "cambio de paradigma" para la educación).

En suma, la construcción de una comunidad de aprendizaje podría ser uno de los fines más elevados de la educación social en el contexto de la globalización. Desde esa perspectiva, la escuela se convertiría en una colaboradora del conjunto de las instituciones educativas y agentes sociales, en la construcción de una nueva sociedad bajo un nuevo contrato social resultado de la globalización, de la economía, las tecnologías y también la equidad y el bienestar social para todos.

\section{Para terminar}

Hoy, estamos comprendiendo, con creciente claridad, que se espera de la educación social la generación de una propuesta educativa que construya ciudadanos responsables, capaces de ayudar a construir una democracia, en consecuencia, participativa y social, en la que se respetan la diversidad y las diferencias, capaz de garantizar a todos el disfrute de los bienes de la modernidad y el pleno ejercicio de la ciudadanía.

Pero debo terminar. Y quiero hacerlo con unas palabras de Eduardo Galeano (1998: 45), en las que yo suelo abrevar mi esperanza en que esta tarea de la educación social es apasionante y merece la pena, sobre todo en momentos difíciles:

"Nosotros tenemos la alegría de nuestras alegrías y también tenemos la alegría de nuestros dolores, porque no nos interesa la vida inodora que la civilización de consumo vende en los supermercados y estamos orgullosos del precio de tanto dolor que por tanto amor pagamos. Nosotros tenemos la alegría de nuestros errores, tropezones que muestran la pasión de andar y el amor al camino, tene mos la alegría de nuestras derrotas porque la lucha por la justicia y la belleza valen la pena también cuando se pierden. Y sobre todo tenemos la alegría de nuestras esperanzas en plena moda del desencanto, cuando el desencanto se ha convertido en un artículo de consumo masivo y universal. Nosotros seguimos creyendo en los asombrosos poderes del abrazo humano".

Es la misma idea que expresó con sencillez, ya en el ocaso de su vida, Freire (1997: 48) un hombre que siempre permaneció radicalmente fiel al pueblo y a sus búsquedas de una genuina educación liberadora: "Reconozco los obstáculos pero rechazo acomodarme en silencio, o simplemente ser el eco vacío, avergonzado o cínico del discurso dominante". 


\section{Referencias bibliográficas}

Bordieu, P. Y Passeron, J. C. (1977): La reproducción. Elementos para una teoría del sistema de enseñanza. Barcelona: Laila.

Borjas, B. (2000): “Globalización, Interculturalidad y Educación Popular". Ponencia presentada en el Foro sobre Globalización y Educación Popular. Maracaibo, Venezuela: Universidad del Zulia.

Delors, J. (1996): La educación encierra un tesoro. In forme de la UNESCO de la Comisión Internacional sobre educación. Madrid: Santillana.

Escudero, J. M. (1999): "La calidad de la Educación: grandes lemas y serios interrogantes". Acción Pedagógica, Vol. 8, N. 2, Universidad de Los Andes, Mérida, Venezuela.

Freire, P. (1970): The pedagogy of the oppresed. New York: Herder \& Herder.

Freire, Paulo (1997): A la sombra de este árbol. Barcelona: Roure.

Friedman, T. (1999): The Lexus and the Olive Tree: Understanding Globalization. New York: Farrar Straus Ginoux .

Galeano, E. (1998): Patas Arriba. La Escuela del mundo al revés. Madrid: Siglo XXI.

González Lucini, F. (1996): Sueño, luego existo. Reflexiones para una pedagogía de la esperanza. Madrid: Alauda-Anaya.

Pérez Gómez, A. (1998): La cultura escolar en la sociedad neoliberal. Morata: Madrid.

PNUD (1997): Informe sobre el desarrollo humano 1997. Madrid: Ediciones Mundi-Prensa.
Tedesco, J. C. (1995): El nuevo pacto educativo. Madrid: Santillana.

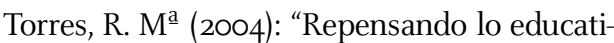
vo desde el desarrollo local y desde el aprendizaje". Documento presentado en el Simposio Internacional sobre Comunidades deAprendizaje.

\section{NOTAS}

${ }^{1}$ http://aug3.augsbur/edu/global/undgrad.html

${ }^{2}$ Proceso mediante el cual los individuos obtienen control de sus decisiones y acciones relacionadas con su salud; expresan sus necesidades y se movilizan para obtener mayor acción política, social y cultural para responder a sus necesidades, a la vez que se involucran en la toma de decisiones para el mejoramiento de su salud y la de la comunidad. (WHO. Health promotion glossary, 1998).

${ }^{3}$ Lo que ha venido a denominarse el efecto Mateo en educación se produce cuando los sectores de la sociedad que más formación han adquirido siguen aprendiendo cada vez más, y los que menos formación han adquirido, olvidan la poca que han adquirido con más facilidad.

Dirección de la autora: Rosa María Rodríguez Izquierdo. Universidad Pablo de Olavide. Dpto. Ciencias Sociales. Carretera de Utrera, Km.1. 41013 Sevilla. Correo electrónico: rmrodizq@upo.es

Fecha de recepción del artículo: 26.IX.2006

Fecha de aceptación definitiva: 28.x.2006 